\title{
Analysis on the Development Status and Prospect of Intelligent Logistics in Hubei Province
}

\author{
Lei Zhang ${ }^{1,2, *}$ \\ ${ }^{1}$ School of Logistics, Wuhan Technology and Business University, Wuhan, China \\ ${ }^{2}$ School of Management, Wuhan University of Technology, Wuhan, China \\ *Corresponding author. Email: 495997665@qq.com
}

\begin{abstract}
Logistics connects production and consumption. Smart logistics will be a strong support for the construction and sustainable development of smart cities. The construction of smart logistics system is inevitably inseparable from the support of artificial intelligence technology represented by "unmanned" technology. This paper analyzes the development problems of intelligent logistics based on the application of "unmanned" technology, and puts forward strategies for the development of intelligent logistics in Hubei Province. Keywords: "unmanned" technology, intelligent logistics, countermeasure research, prospect
\end{abstract}

\section{INTRODUCTION}

Logistics between production and consumption, as well as city and advantage industries, pillar industries directly affect the traffic load of city, city logistics. Logistics will be the wisdom and strong support for the sustainable development of urban construction, in terms of domestic building intelligent logistics system is represented by "unmanned" technology of artificial intelligence technology support. How to develop the intelligent logistics and construct the intelligent logistics system should arouse the new understanding of the academic and practical fields.

\section{LITERATURE REVIEW}

The first year is wisdom for the development of logistics industry in 2009, IBM put forward the concept of "smart supply chain", through the sensors, RFID tags, brake, GPS and other equipment and systems to establish intelligent supply chain system based on the future, with advanced, interconnected and intelligent three major characteristics of the intelligent supply chain has attracted the attention of experts and scholars, the resulting "wisdom logistics". In December of the same year, the Information Center of China Association of Logistics Technology, China Internet of Things, and the Editorial Department of Logistics Technology and Application jointly put forward the concept of "Smart Logistics", and conducted a series of studies around the concept characteristics, system structure, implementation framework, development trend and other issues.

At present, intelligent logistics has been studied at home and abroad and some results have been achieved. In foreign countries, Matej Kovalsky, Branislav Micieta took the automobile industry as an example to plan and optimize the intelligent logistics system[1]; Duncan McFarlane,
Vaggelis Giannikas, Wenrong Lu studied how to improve the role of customers in intelligent logistics operation [2]. The domestic research on intelligent logistics is mainly reflected in: he Liming, president of China Federation of Logistics and Purchasing, pointed out that at present, the policy environment for the development of intelligent logistics continues to improve, the logistics Internet has been gradually formed, and logistics big data has been applied. Logistics cloud services to strengthen security, collaborative sharing boost model innovation, artificial intelligence is in its infancy. In the future, there will be seven major upgrades, such as connection upgrade, data upgrade, model upgrade, experience upgrade, intelligent upgrade, green upgrade, supply chain upgrade and so on[3]. Wang Zhitai believes that intelligent logistics is not only a technical problem, but also a systematic and comprehensive concept, especially it should be combined with urbanization[4]. Luo Renshu constructed the intelligent logistics information platform[5]. Wang Yu studied the realtime risk management mechanism of intelligent logistics from the perspective of "Internet + "[6].

Intelligent logistics refers to the effective integration and application of Internet of Things technology, big data mining and analysis technology, perception and identification technology, remote monitoring technology and artificial intelligence technology in all links and subjects of logistics activities. It is an efficient logistics system with the ability of thinking, perception, learning, reasoning and judgment, and self-solving.

Smart logistics is the comprehensive introduction and full use of the Internet of Things, cloud computing, big data, "Internet +" and other emerging information technologies, to achieve the development of modern logistics industry "intelligent". Foreign smart logistics industry developed earlier and focused on the application field, while domestic smart logistics industry research is still in the initial stage, mainly focusing on the concept of smart logistics, the construction of smart logistics information system, and the combination of smart logistics with other fields. 


\section{APPLICATION OF "UNMANNED" TECHNOLOGY IN THE CONSTRUCTION OF INTELLIGENT LOGISTICS SYSTEM}

The technical aspects mainly consist of two aspects. One is the key technology, that is, through sensors, RFID tags, brakes, GPS and other equipment and system generated real-time information, in each link of the logistics, each field, especially in the unmanned car, unmanned warehouse, unmanned cabinet, logistics robots and other fields, to achieve efficient allocation of logistics resources and logistics link optimization. Second, infrastructure equipment, especially intelligent equipment represented by unmanned warehouses, intelligent distribution stations and intelligent load vehicles and other facilities and equipment, is an important basis for the long-term development of the logistics industry.

In recent years, with the rapid development of e-commerce, logistics demand, driven by the innovation of many emerging information technologies, intelligent delivery robots, automatic cargo sorting system, intelligent monitoring system and other new technologies are triggering a new round of changes in the logistics industry, and the logistics industry is experiencing intelligent upgrading. From the past to equipment, labor to dividends, into technology, synergy to benefit. Among them, the extensive use of a large number of intelligent robots in the "unmanned" warehouse has greatly improved the efficiency of parcel storage and sorting. "Unmanned" delivery technology, dominated by unmanned delivery vehicles, unmanned aerial vehicles and other modes of transportation, has created a huge development space for the optimization of distribution routes.

\section{MAJOR CHALLENGES FOR SMART LOGISTICS IN HUBEI}

The sudden outbreak, the mass transport and express logistics distribution to ensure Hubei medical supplies and play an important role in people's basic living supplies demand, but at the same time also should see, in the infrastructure needed wisdom logistics development gap with the real demand is very big, the end of the intelligence service level is not high, "the last kilometer" is also very dependent on human, Especially in the case of the need to avoid human contact and infection, there is still a considerable distance between the "unmanned" technology and its actual role, which highlights the deficiency of the current development of intelligent logistics and the huge space for future development.

\subsection{The Intelligent Service Level at the End of Intelligent Logistics Is Not High}

At present, the "last mile" of logistics is still heavily dependent on human labor; With the development of a higher level of express industry for example, whether it is receiving goods or delivery, its intelligent service level is relatively low. At present, express delivery cabinets have become the standard distribution of urban logistics terminals, but there are many problems in the placement and configuration of express delivery cabinets. For example, some consumers in residential communities have no cabinets available, and some express delivery cabinets in residential communities are idle. It is not difficult to see that in the development process of intelligent logistics, the terminal intelligent service has not been normalized and the intelligent service level is not high. In the face of an outbreak, especially in the case of the need to avoid human contact and infection, express delivery can not enter the community, which highlights the reality gap of the "unmanned" technology of smart logistics.

\subsection{Insufficient Construction of Logistics Information Platform}

Logistics information platform is a technical platform to ensure the efficient operation of logistics and a collaborative platform to integrate logistics services. The development of intelligent logistics cannot be separated from the support of logistics information platform. At present, many enterprises have begun to use the Internet of things technology to build intelligent logistics system, but the logistics enterprise scale is small, scattered layout, management confusion, province within the scope of distribution imbalance, and the lack of effective management measures, management confusion, hard to the free flow of production factors, the allocation of resources is not optimized, it is difficult to form a unified, open, orderly market, Especially the lack of giant leading enterprises to drive, it is difficult to form industrial clusters. Most small and medium-sized enterprises are struggling in the aspect of logistics informatization. Due to the lack of corresponding talents and funds, the management level does not attach enough importance to the application of information technology. Even if relevant intelligent logistics technology is introduced, supporting infrastructure can not keep up with it, resulting in no significant improvement of enterprise benefits. Small and mediumsized enterprises lack of information means to deploy the transport of vehicles, in the transport capacity of $40 \%$ of the state is empty, often overload when going out, back time and space load, resulting in very high logistics costs. At present, there are a number of enterprises engaged in smart logistics in the province, such as Wuhan Yangtze River Intelligent Logistics, Sinotrans, Jingdong, etc. The government has also carried out a lot of research and investment in the development of smart logistics. However, compared with the United States, Japan and other developed countries and domestic developed provinces, smart logistics is still in the initial stage. In the face of this outbreak, the construction of logistics information platform of smart logistics is more prominent. 


\subsection{The Construction of Smart Logistics Infrastructure Is Relatively Backward}

Smart logistics cannot be separated from the hardware support of traditional logistics infrastructure. At present, the infrastructure is still insufficient, constrained by the lack of unified provincial market construction level, and the regionalization is still serious. The "chess game" of logistics infrastructure is a mere formality, and the level of logistics infrastructure in different places is uneven. For example, the logistics equipment used by logistics enterprises is relatively backward. Even for some large logistics enterprises, less than $40 \%$ of the logistics equipment can be directly connected to the logistics information system, so it is difficult to form an integrated effect. In this outbreak, in order to avoid human contact, a large number of vehicles transporting goods and materials to Hubei need the provincial vehicles to receive and unload the transferred goods and materials in the park. However, the serious shortage of vehicles and the problems of the site for the transfer of goods and materials have caused difficulties for the transfer of goods and materials.

\subsection{The Foundation of Logistics Information Standardization Needs to Be Strengthened}

Intelligent logistics is based on the standardization of logistics information, which requires standardization in codes, file formats, data interfaces, electronic data interchange (EDI), global positioning system (GPS) and other related codes, in order to eliminate information communication barriers between different enterprises. In the developed countries have established in bar code and information exchange interface, a set of practical standards make logistics enterprise with customers, subcontractors and suppliers more facilitate communication and services, logistics software also blended in format, the process of industry standards, create a good environment for enterprise logistics information system construction. In Hubei Province, due to the lack of basic information standards, the interface of different information systems has become the bottleneck restricting the development of informatization, leading to the construction of logistics standardization system is not perfect, and the establishment and modification of logistics informatization business standards and technical standards can not keep up with the needs of the development of logistics informatization. Many logistics information platforms and information systems follow their own norms, which makes it difficult to realize information exchange and sharing among enterprises, platforms and organizations. The situation of "serving each other in formation and land enclosure" is common. It is difficult for the entire electronic logistics network to be compatible, data exchange and information sharing. It makes it difficult to form a complete and unobstructed supply chain from production, circulation to consumption and other links, which seriously affects the management of logistics industry and the operation of e-commerce. In the outbreak of the epidemic, a variety of platforms, a variety of logistics enterprises for their own battle, each reflects the great lack of logistics information standardization basis.

\subsection{Serious Shortage of Complex Logistics Professionals}

Only the formation of intelligent logistics system can give full play to the role of wisdom, which requires not only the investment of policies and funds, but also the cultivation and accumulation of complex logistics professionals, which is the root of restricting the development of intelligent logistics in Hubei Province.

Compared with Beijing, Shanghai, Guangdong and other regions, Hubei is short of top talents in logistics complex professional field. Compared with Beijing, Shanghai, Guangdong and other regions, Hubei has not formed a strong industrial agglomeration effect, and it is difficult to attract and retain enough high-level talents, especially the lack of complex high-end talents in logistics. In recent years, although Hubei's attraction to talents has increased significantly, there is still a huge talent gap due to the lack of industrial volume, weak foundation, employment opportunities, development space, salary level and other factors. Hubei province has a large number of universities. Wuhan University, Huazhong University of Science and Technology and other relevant majors have strong strength, which has cultivated a large number of talents, but most of them have flowed to developed regions. Although in recent years, the talent pool in Beijing, Shanghai, Guangzhou and Shenzhen is gradually saturated, Hangzhou, Chengdu and other places show stronger competitiveness in attracting talents. In the competition for the development of smart logistics, Hubei has once again fallen into the crisis of "talent depression".

\section{STRATEGIES FOR THE DEVELOPMENT OF SMART LOGISTICS IN HUBEI}

The follow-up of a major event will put forward higher requirements for the corresponding policies and industries. After the epidemic, the development of smart logistics will certainly bring greater requirements for upgrading.

Smart logistics involves many industries, which cannot be separated from the strong support of the government. First, we should take the initiative to adapt to the development trend of smart logistics and strengthen the cooperation between the government and departments. We should firmly grasp the nature and characteristics of intelligent logistics, strengthen information communication between the government and departments, realize dynamic management of logistics information, and construct a management system of intelligent logistics. Governments at all levels should strengthen coordination and introduce more policies conducive to the development of smart logistics, so as to escort the development of smart logistics. Second, we 
should increase the support for smart logistics enterprises, use financial funds to establish encouraging development funds, select and support a group of advanced technology and strength of smart logistics enterprises, so that they become the industry development leader. Preferential policies can be provided for logistics enterprises in terms of tax reduction, land use preference and construction of smart logistics parks. Smart logistics enterprises are encouraged to explore sharing and cooperation models and use big data technology to effectively integrate the idle logistics facilities of all kinds of enterprises, such as warehouses, containers, pallets and vehicles, so as to continuously improve the coverage rate and service efficiency of smart logistics and reduce the operating costs of smart logistics.

\subsection{Formulate Long-Term Logistics Development Plan and Improve Relevant Policies and Regulations}

Due to the unbalanced distribution of logistics resources in the province, small scale of logistics enterprises and relatively backward management methods, the provincial government needs to formulate long-term development plans for the logistics industry, issue development policies for the logistics industry, and apply new sensing technology, mobile computing technology, wireless network transmission technology, etc. Establish a product traceability network system, logistics process visualization intelligent management network system, intelligent supply chain enterprise logistics distribution center and wisdom, foster a batch of informatization level is high, the wisdom of the demonstration role in driving the strong logistics demonstration enterprises, at the same time a batch of excellent demonstration enterprises can be converted to the third party logistics enterprise, so as to drive the development of other enterprises in the same industry. In addition, the transportation infrastructure and freight channel network planning closely related to logistics also need to be further improved. Formulate relevant legal norms, and create a fair and orderly market environment, is conducive to eliminate market barriers between regions, the factors of production can flow freely, so as to optimize the allocation of resources, form a unified, open, orderly market, to better protect the legitimate rights and interests of operators and maintenance logistics users legitimate interests, realize the legalization, standardization and institutionalization of the logistics industry. In terms of fiscal policy, to the wisdom logistics project as a key support project, set up the mechanism of dynamic financial guarantee effective government support, to promote fiscal special funds and tax breaks to wisdom and logistics applications, logistics technology and product research and development, the wisdom logistics industry base construction, to accelerate the development of intelligent logistics. In the early stage of key projects of smart logistics, most of the construction funds can be invested by the government and part of social funds can be attracted at the same time. They can be operated and managed in the mode of non-profit enterprises. In the middle period of project construction, the government and the society can invest funds in accordance with a certain proportion and operate and manage the project in accordance with the enterprise mode. At the end of the project construction, most of the funds can be invested by the society, and the government will give certain subsidies to implement market-oriented operation and management.

\subsection{Accelerate the Construction of Intelligent Logistics Information Standardization}

The key to the development of intelligent logistics is to realize the seamless connection of all enterprises and all logistics links in the logistics supply chain through advanced logistics information technology, so as to realize the integrated operation of the whole logistics supply chain. On the one hand, we should speed up the construction of intelligent logistics standardization system. By drawing on advanced experience at home and abroad and combining with the development reality of smart logistics, the standardization system of smart logistics should be constructed to cover all links and fields of smart logistics. In particular, the cross-industry, cross-department and cross-enterprise cooperation of smart logistics must be clearly stipulated so as to truly realize the standardization of business process of smart logistics. On the other hand, the standardization of basic information of smart logistics should be accelerated. Including bar code, RFID and so on should develop a unified collection standard; At the same time, the logistics information exchange and docking are standardized to realize the smooth docking between different information systems. Through the construction of information standardization, the different and unaffiliated logistics links can operate in accordance with the unified standard.

\subsection{Accelerate the Construction of Logistics Information Platform}

Wisdom logistics is a service oriented, efficient, intelligent and integration of modern logistics operation mode, wisdom logistics operation without the support of the information platform of logistics information platform as a geared to the needs of the entire logistics system, integration, intelligent information management center of logistics, logistics is to achieve efficient operation and technical platform of integrated logistics service providers. Use of the Internet of things, cloud computing and Internet technology to build a wisdom logistics information platform, real-time to provide goods distribution, intelligent tracing, customer query information service, information platform combines information release, product display, and other functions into an organic whole, can solve the technical problems of the traditional logistics platform, make solid landing platform, create real value for enterprises and users, Its important demonstration and driving effect will accelerate 
the development of modern logistics industry. The development of smart logistics needs information interconnection and sharing, and the innovation of smart logistics mode also needs the input and participation of government information. The interconnection and sharing of information is an urgent problem to be solved in the process of improving the intelligent logistics supply chain. The government can improve the policy environment and regulatory system, improving the information exchange system and open standards, and accelerate the government logistics data information open to the whole society and sharing, prompting logistics information connectivity and open sharing, so as to effectively eliminate information barriers and problem of "information island", fully release wisdom logistics development potential, Improve logistics efficiency and service level.

\subsection{To Perfect the Terminal Service System of Intelligent Logistics}

The terminal service system is the key to the smooth operation of the whole intelligent logistics and the expected results. In view of the problems existing in the current terminal service system, one is to integrate e-commerce, Internet of Things and other resources to create an intelligent logistics terminal service system. The focus is to strengthen the in-depth cooperation between e-commerce and modern logistics enterprises, use cloud computing, big data and other information technologies, accelerate the promotion of unmanned delivery, joint delivery and other smart logistics models, improve the level of smart logistics delivery intensive, and effectively solve the "last mile" problem of logistics distribution. Second, it is necessary to accelerate the automation of logistics terminal. From automated warehouse, sorting machines to electronic label picking, robot picking, and then to automated sorting, storage, shipping and other logistics operations, all of the automation. Replace manual work with automatic machines to greatly improve the distribution efficiency of smart logistics. The third is to improve the coverage of the terminal service system. Promote logistics and distribution enterprises more into the community, toward the countryside, and community service stations, convenience stores, schools, property companies and other cooperation, scientific deployment of intelligent express cabinets, express stations, so that the intelligent logistics coverage to more areas, effectively reduce the cost of intelligent logistics terminal service, improve its service efficiency.

\subsection{To Optimize the Talent Environment and Accelerate the Training of Complex Logistics Professionals}

Different from the traditional logistics industry, which is labor-intensive, smart logistics shows the characteristics of science and technology intensive. Therefore, the strength of regional scientific and technological innovation ability will affect the sustainability of the development of smart logistics, and researchers are the main body of regional scientific and technological innovation, and the key to regional scientific and technological competition in the future. Hubei province has rich resources of science and education, and create a good scientific research talents growth environment is the key to retaining talent, attract talent, therefore, Hubei government entities at all levels should continue to optimize the environment of talent growth, from housing subsidies, therapy, children education aspects of constructing the scientific talent training, talent recruit, talent growth mechanism, the rich resources of science and education into talent advantage. Wisdom logistics, on the other hand, compared with the traditional logistics industry to the laborer quality put forward higher requirements, continuously improve the scientific and cultural quality of logistics practitioners is to adapt the inevitable requirement of the intelligent logistics development, therefore, the logistics industry of hubei province relevant government departments, industry associations can vocational training mode innovation, guide the logistics enterprises to strengthen the training of managers, frontline staff re-education, To provide a solid talent base for the development of intelligent logistics in Hubei.

At present, many departments and colleges and universities have set up specialized logistics management subjects or scientific research projects. It is necessary to innovate the talent training mode, rely on colleges and universities and training institutions to synchronize the logistics education with the development of the industry, strengthen the training of talents in core technology research and development and the construction of innovation team, so as to cultivate the talents that enterprises really need. And related policies and measures, imposed on the long-term, more talents cultivation, introduction and use of policy support, integration of colleges and universities, research institutes, software enterprises and other institutions resources, focus on cultivating innovative, managed, through various channels, and high skilled talents, provide intellectual support for the wisdom logistics development. To draw lessons from the experience of advanced countries, and constantly improve the mechanism for attracting foreign logistics professionals, establishing talent incentive mechanism, intensify their efforts to introduce talents and targeted the introduction of the Internet of things, cloud computing, information technology services in the areas of high-end talent, wisdom, logistics management, further improve the service of market mechanism, improve logistic talent liquidity of wisdom, To promote the sustainable and healthy development of intelligent logistics.

\section{CONCLUSION}

We will accelerate the development of smart logistics infrastructure and improve the mechanism for training talents. Through the reference and the beneficial experience of the developed countries for reference, to increase investment channels for modern logistics industry, 
encourage private and diverse patterns of social capital into the circulation field, reasonable construction and convenient layout efficient modern logistics infrastructure network system, as soon as possible to establish a unified and open operation efficiency, competitive and orderly regional or national logistics service market, To promote the healthy and orderly development of China's modern logistics industry.

We will accelerate the construction of an intelligent logistics information system and increase government support. The government financial support for modern logistics information system, establish long-term financial special funds or tax reduction and other financial guarantee mechanisms, regard the development of smart logistics as the key or priority support project of governments at all levels, and vigorously encourage and support logistics enterprises through mergers and acquisitions, alliance restructuring and strategic cooperation. Accelerate the transformation and upgrading of traditional logistics enterprises to modern logistics enterprises.

We will accelerate the improvement of smart logistics development plans and further improve the system. At present, China's logistics enterprises have many problems such as small scale of operation, unbalanced distribution between urban and rural areas and backward operation and management concepts, which seriously restrict the rapid development of China's smart logistics industry. Therefore, it is necessary to speed up the formulation of smart logistics development plans, improve policies to promote the development of smart logistics, and speed up the promotion and application of modern information technology in the field of logistics, such as new sensing technology, Beidou navigation, wireless network transmission technology and other modern information technology.

\section{AUTHORS' CONTRIBUTIONS}

This paper analyzes the shortcomings of the traditional logistics system brought by the epidemic, studies the development of intelligent logistics based on the application of "unmanned" technology, and puts forward strategies for the development of intelligent logistics in Hubei Province through research.

\section{ACKNOWLEDGMENT}

This paper is supported by: (1) Hubei Business Service Development Research Center Fund project: Hubei Intelligent Logistics Development support system Research (2020Z01). (2) Doctoral Research Foundation of Wuhan Institute of Industry and Technology: Analysis and Countermeasures of Cross-border Logistics Security of Petroleum projects in China and Kazakhstan based on "Belt and Road Initiative" (D2019004).

\section{REFERENCES}

[1] Kovalsky M, Mi I B. Support Planning and Optimization of Intelligent Logistics Systems[J]. Procedia Engineering, 2017, (192): 451-456.

[2] McFarlane D, Giannikas V, Wenrong L.Intelligent Logistics: Involving the Customer[J] .Computers in Industry, 2018, 81(9): 105-115.

[3] Liming H. Development Trend of Intelligent Logistics in China[J]. China's Circulation economy, 2017, (6): 3-7. (In Chinese).

DOI:https://doi.org/10.14089/j.cnki.cn113664/f.2017.06.001.

[4] Zhitai W. Urbanization Needs Intelligent

Logistics[J]. China's Circulation economy, 2014, (3): 4-

8. (In Chinese).

DOI:https://doi.org/10.3969/j.issn.1007-

8266.2014.03.001.

[5] Renshu L. The Construction of Intelligent Logistics Information Platform[J]. Logistics Engineering and Management,2014,(1):80-81.

DOI:https://doi.org/10.3969/j.issn.16744993.2014.01.031.

[6] Yu W, Lifang G, Jiaqi M. Research on Real-time Risk Management Mechanism of Intelligent Logistics from the Perspective of Internet $+[\mathrm{J}]$. Management Modernization, 2018,(1):98-101.(In Chinese).

DOI:https://doi.org/10.19634/j.cnki.111403/c.2018.01.028. 